\title{
THE BLOOD FLOW, VASCULAR RESISTANCE, AND OXYGEN CONSUMPTION OF THE BRAIN IN ESSENTIAL HYPERTENSION ${ }^{1}$
}

\author{
By SEYMOUR S. KETY, JOSEPH H. HAFKENSCHIEL, WILLIAM A. JEFFERS, \\ IRVING H. LEOPOLD, AND HENRY A. SHENKIN
}

(From the Departments of Pharmacology, Medicine, Ophthalmology and Surgery, University of Pennsylvania, Philadelphia)

(Received for publication December 4, 1947)

The vascular bed of the brain should occupy a prominent place among the regions of interest to the clinical investigator who would seek to define the circulatory disturbances associated with hypertension. The vulnerability of cerebral arteries in chronic hypertensive disease has long been recognized. Statistical surveys demonstrate that about $15 \%$ of deaths in hypertension are the result of cerebrovascular lesions ( 1 to 3 ). Many hypertensive patients experience symptoms such as headache, dizziness, and tinnitus, which are probably referable to the brain. Furthermore it has been suggested that some of the etiological factors in hypertension may be of cerebral origin.

Knowledge of the cerebrovascular resistance and cerebral blood flow in human hypertension has been extremely limited. The well-recognized changes observed in retinal vessels, in the absence of more specific information, have been presumed to reflect similar phenomena in the cerebral vascular bed. Measurement of cerebral blood flow in this disease has been limited to studies of cerebral arteriovenous oxygen differences $(4,5)$ which become an index of blood flow only after cerebral metabolism can be measured or shown to be normal.

The nitrous oxide method for the quantitative measurement of human cerebral blood flow $(6,7)$ found its first application to clinical disease in a study on five patients with various degrees of arterial hypertension (8). The present study represents a more complete investigation on 13 additional patients.

\section{METHODS}

Patients in whom nearly uncomplicated essential hypertension existed were selected from the medical or surgical services. Cerebral blood flow (CBF) was determined by the nitrous oxide method (7), with the use of a gas mixture consisting of $15 \% \mathrm{~N}_{2} \mathrm{O}, 64 \% \mathrm{~N}_{2}, 21 \% \mathrm{O}_{2}$. Mean

1 The expenses of these studies were defrayed by a grant from the Life Insurance Medical Research Fund. arterial blood pressure (MABP) was obtained by means of a damped mercury manometer attached to a needle in the femoral artery. Cerebral metabolic rate in terms of cerebral oxygen consumption $\left(\mathrm{CMR}_{\mathrm{O}_{2}}\right)$, and cerebrovascular resistance (CVR) were calculated as previously described (7). Blood gas analyses were made with the Van Slyke-Neill manometric apparatus (9). Potentiometric measurement of blood $\mathrm{pH}$ was made anaerobically at $37^{\circ} \mathrm{C}$. by means of a glass electrode. Values for blood carbon dioxide tension were calculated by means of the nomograms presented by Peters and Van Slyke (9).

\section{RESULTS}

The data obtained in these measurements are presented in Table I. There is little deviation from the normal in most of the values found. There is an even distribution between the sexes, but most of the patients lie in one age group-the fifth decade of life. It should be pointed out that the normal values presented for comparison were obtained in a series of young men in the third decade (7). We have observed no measurable trend in any of our data to suggest that normal values in middleaged individuals differ significantly from those in somewhat younger subjects.

The mean arterial blood pressures in this series range from 124 to $190 \mathrm{~mm}$. of mercury, the average value of $159 \mathrm{~mm}$. being $89 \%$ above the normal of $86 \mathrm{~mm}$. Values for the carbon dioxide content and tension, $\mathrm{pH}$, and oxygen content of arterial and internal jugular blood are within normal limits.

Cerebral blood flow, cerebral oxygen consumption, and cerebral arteriovenous oxygen difference are all practically identical with mean normal values. The cerebral respiratory quotient

$$
\text { (cc. } \mathrm{CO}_{2} \text { produced } \text { cc. } \mathrm{O}_{2} \text { consumed the brain) }
$$

is slightly but significantly depressed below the average normal value of 0.99 . The most striking deviation from the normal observed in the entire study is the marked and consistent elevation of 
TABLE I

Blood gases and cerebral circulation and metabolism in essential hypertension

\begin{tabular}{|c|c|c|c|c|c|c|c|c|c|c|c|c|c|c|c|c|c|c|}
\hline \multirow[b]{2}{*}{ Pt. } & \multirow[b]{2}{*}{$\begin{array}{l}\text { Age } \\
\text { yrs. }\end{array}$} & \multirow[b]{2}{*}{ Sex } & \multirow[b]{2}{*}{ Color } & \multirow{2}{*}{$\begin{array}{c}\text { Reti- } \\
\text { no- } \\
\text { pathy } \\
\text { grade }\end{array}$} & \multicolumn{5}{|c|}{ Arterial } & \multicolumn{5}{|c|}{ Internal jugular } & \multicolumn{4}{|c|}{ Cerebral } \\
\hline & & & & & B. P. & $\begin{array}{l}\mathrm{CO}_{2} \\
\text { con- } \\
\text { tent }\end{array}$ & $\begin{array}{l}\mathrm{CO}_{2} \\
\text { ten- } \\
\text { sion }\end{array}$ & pH & $\begin{array}{c}\mathrm{O}_{2} \\
\text { con- } \\
\text { tent }\end{array}$ & $\begin{array}{l}\mathrm{CO}_{2} \\
\text { con- } \\
\text { tent }\end{array}$ & $\begin{array}{l}\mathrm{CO}_{2} \\
\text { ten- } \\
\text { sion }\end{array}$ & $\mathrm{pH}$ & $\begin{array}{c}\mathrm{O}_{2} \\
\text { con- } \\
\text { tent }\end{array}$ & $\begin{array}{c}\mathrm{A}-\mathrm{V} \\
\mathrm{O}_{2}\end{array}$ & CBF & $\underset{\mathrm{O}_{2}}{\mathrm{CMR}}$ & CVR & $\mathbf{R Q}$ \\
\hline $\begin{array}{l}\text { M. O. } \\
\text { F. H. } \\
\text { B. P. } \\
\text { G. J. } \\
\text { W. M. } \\
\text { J. M. } \\
\text { R. O. } \\
\text { L. S. } \\
\text { H. K. } \\
\text { M. Mc. } \\
\text { L. T. } \\
\text { L. R. } \\
\text { N. B. } \\
\text { Mean } \\
\text { Mean va } \\
\text { males }\end{array}$ & $\begin{array}{l}40 \\
54 \\
37 \\
48 \\
47 \\
49 \\
34 \\
48 \\
38 \\
47 \\
46 \\
47 \\
51 \\
45\end{array}$ & $\begin{array}{l}\mathbf{F} \\
\mathbf{F} \\
\mathbf{F} \\
\mathbf{M} \\
\mathbf{F} \\
\mathbf{M} \\
\mathbf{M} \\
\mathbf{M} \\
\mathbf{F} \\
\mathbf{F} \\
\mathbf{M} \\
\mathbf{M} \\
\mathbf{F}\end{array}$ & $\begin{array}{l}\mathbf{W} \\
\mathbf{W} \\
\mathbf{W} \\
\mathbf{C} \\
\mathbf{C} \\
\mathbf{C} \\
\mathbf{W} \\
\mathbf{W} \\
\mathbf{W} \\
\mathbf{W} \\
\mathbf{C} \\
\mathbf{W} \\
\mathbf{W}\end{array}$ & $\begin{array}{l}\text { IV } \\
\text { II } \\
\text { II } \\
\text { III } \\
\text { II } \\
\text { III } \\
\text { III } \\
\text { II } \\
\text { IV } \\
\text { I } \\
\text { II } \\
\text { II } \\
\text { III } \\
\text { Ing }\end{array}$ & $\begin{array}{c}\underset{H g}{\mathrm{~mm}} \\
\mathrm{Hg} \\
190 \\
124 \\
159 \\
161 \\
155 \\
166 \\
158 \\
171 \\
190 \\
175 \\
137 \\
157 \\
126 \\
159 * \\
86\end{array}$ & $\begin{array}{c}\text { yol. } \\
\% \\
44.2 \\
50.8 \\
41.2 \\
47.5 \\
50.1 \\
56.8 \\
56.3 \\
52.3 \\
49.8 \\
47.6 \\
49.9 \\
47.6 \\
49.9 \\
49.5 \\
49.4\end{array}$ & $\begin{array}{c}\underset{H g}{\mathrm{~mm}} \\
31 \\
43 \\
35 \\
\\
40 \\
45 \\
48 \\
43 \\
41 \\
42 \\
46 \\
41 \\
\\
41 \\
42\end{array}$ & $\begin{array}{l}7.50 \\
7.40 \\
7.40 \\
\\
7.42 \\
7.42 \\
7.39 \\
7.41 \\
7.41 \\
7.37 \\
7.36 \\
7.39 \\
7.41 \\
7.40\end{array}$ & \begin{tabular}{|c|} 
vol. \\
$\%$ \\
17.5 \\
17.6 \\
18.3 \\
17.8 \\
16.2 \\
15.8 \\
16.4 \\
17.7 \\
16.6 \\
15.9 \\
17.6 \\
18.1 \\
16.1 \\
17.0 \\
17.3
\end{tabular} & \begin{tabular}{|c|} 
vol. \\
$\%$ \\
49.5 \\
57.5 \\
47.4 \\
53.8 \\
57.3 \\
62.1 \\
61.7 \\
57.1 \\
55.5 \\
52.6 \\
55.4 \\
52.8 \\
54.9 \\
55.2 \\
55.4
\end{tabular} & $\begin{array}{c}\underset{H g}{m} . \\
37 \\
50 \\
42 \\
\\
51 \\
56 \\
62 \\
52 \\
50 \\
50 \\
56 \\
52 \\
51 \\
51\end{array}$ & $\begin{array}{l}7.45 \\
7.37 \\
7.37 \\
7.36 \\
7.35 \\
7.31 \\
7.36 \\
7.36 \\
7.34 \\
7.31 \\
7.32 \\
7.36 \\
7.34\end{array}$ & 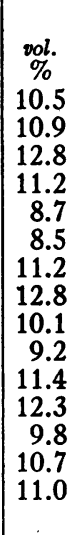 & \begin{tabular}{|l} 
vol. \\
$\%$ \\
7.0 \\
6.7 \\
5.5 \\
6.6 \\
7.6 \\
7.3 \\
5.2 \\
4.9 \\
6.5 \\
6.7 \\
6.2 \\
5.8 \\
6.2 \\
6.3 \\
6.3
\end{tabular} & \begin{tabular}{|c|}
$c c . / 100$ \\
$g . / \min$. \\
54 \\
56 \\
63 \\
52 \\
47 \\
45 \\
52 \\
64 \\
59 \\
52 \\
55 \\
54 \\
44 \\
54 \\
54
\end{tabular} & \begin{tabular}{|c}
$c c . / 100$ \\
$g . / \min$. \\
3.8 \\
3.8 \\
3.5 \\
3.4 \\
3.5 \\
3.3 \\
2.7 \\
3.1 \\
3.8 \\
3.5 \\
3.4 \\
3.1 \\
2.7 \\
3.4 \\
3.3
\end{tabular} & \begin{tabular}{|c|}
$\frac{m m . H_{g}}{c c . / 100}$ \\
$\mathrm{~g} . / \min$. \\
3.5 \\
2.2 \\
2.5 \\
3.1 \\
3.3 \\
3.7 \\
3.0 \\
2.7 \\
3.2 \\
3.4 \\
2.5 \\
2.9 \\
2.9 \\
$3.0^{*}$ \\
1.6
\end{tabular} & $\begin{array}{l}0.77 \\
1.00 \\
1.13 \\
0.95 \\
0.95 \\
0.73 \\
1.04 \\
0.98 \\
0.88 \\
0.75 \\
0.89 \\
0.90 \\
0.79 \\
0.90^{*} \\
0.99\end{array}$ \\
\hline
\end{tabular}

* Signifies statistically significant differences from the normal.

cerebrovascular resistance, a measure of the tone of cerebral vessels obtained by dividing the cerebral blood flow into the mean arterial blood pressure (7). Whereas in the normal brain a pressure head of $1.6 \mathrm{~mm}$. of mercury is necessary to produce a flow of $1 \mathrm{cc}$. of blood per 100 grams of brain per minute, a pressure of $3.0 \mathrm{~mm}$. or nearly twice the normal produces the same flow through the brain of hypertensive patients.

\section{DISCUSSION}

Observers who have made clinical measurements of blood flow in various organs of hypertensive patients have found a relatively normal volume flow of blood in the face of a considerably elevated perfusion pressure in the arterial system. In the body as a whole, total blood flow (i.e., cardiac output) has been found to be relatively normal in hypertension by Bradley and Smith (10) who used the ballistocardiograph, and Goldring, Chasis, Ranges, Lauson, and Cournand (11) who employed the direct Fick principle. Skin temperature measurements (13) and observations with the occlusion plethysmograph $(14,15)$ indicate a normal peripheral blood flow in this disease. The studies of Goldring, Chasis, Ranges and Smith (16) on renal blood flow in hypertensive patients indicate that renal blood flow per mass of functional excretory tissue is reduced very slightly, if at all. Work recently reported by Wilkins and collaborators (17) demonstrates that blood flow through the abdominal viscera is not altered by the presence of hypertension.

To this list of organs in which clinical blood flow measurements have been made in hypertension the brain may now be added. Our results in the present series and its precursor (8) demonstrate for the first time that cerebral blood flow is within normal limits in patients with uncomplicated essential hypertension. The mean value of $54 \mathrm{cc} . / 100 \mathrm{~g} . / \mathrm{min}$. presented in Table I is identical with the mean for normal subjects (7). The average of the five cases in the preliminary report (after correction of the brain/blood partition coefficient for nitrous oxide from the earlier estimate of 1.3 to the more exact value of 1.0 [18]) was $49 \mathrm{cc} . / 100 \mathrm{~g} . / \mathrm{min}$., representing a difference from the present study which is not statistically significant.

A normal cerebral blood flow in the presence of a high mean arterial blood pressure can only mean an increase in the resistance to the flow of blood offered by the cerebral vascular bed. 'Calculation of this cerebrovascular resistance in these 
patients shows an increase over the normal of $88 \%$. It is further apparent that if the blood flow in other vascular beds such as the kidney, the abdominal viscera, extremities, skin and the total cardiac output are not increased in this condition, as indeed all the experimental evidence previously cited demonstrates, then an increase in vascular resistance of at least equal magnitude must occur in each of these circulatory beds and in the body as a whole. Thus the brain shares in equal measure the generalized increase in vascular tone which is associated with hypertension.

The cerebral arteriovenous oxygen difference in this series yielded a mean value (6.3 vol. \%) identical with that found by us in normal subjects (7). This is in accord with the findings of Williams and Lennox (4) who obtained a normal cerebral arteriovenous oxygen difference on 21 hypertensive patients. Raab (5), on the other hand, reported a mean value of 7.7 vol. $\%$ in ten patients with this disease and concluded that relative medullary ischemia may have been responsible for the hypertension. A possible explanation for this discrepancy may be the greater age and the more advanced state of the hypertension in the patients studied by Raab. Our finding of a normal cerebral blood flow and normal hydrogen ion, $\mathrm{CO}_{2}$ and oxygen concentrations in the internal jugular blood of a younger group of hypertensives speaks against cerebral ischemia as a primary factor in essential hypertension.

Examination of Table I reveals some correlation between the cerebrovascular resistance and the grade of retinopathy even though the four grades are not evenly represented. If these 13 patients plus three normals and the five hypertensives previously reported are ranged in order of increasing severity of retinal vascular changes and of increasing cerebrovascular resistance, a coefficient of correlation may be obtained with a high order of significance $(r=0.66, p=0.001)$. Thus the clinical impression that the retinal vessels reflect the state of the vessels of the brain appears to be substantiated by these quantitative observations. A future report on a larger and more representative series will concern itself specifically with this aspect of the subject.

The present extent of our data permits no conclusion as to the sequence of events between the hypertension and the cerebrovascular hypertonus. The classic studies of Cushing (19), recently confirmed by us in man (20), demonstrate that restriction of cerebral blood flow may result in a compensatory increase in blood pressure. Perhaps similar phenomena are the hypertensive states experimentally produced by Dixon and Heller (21) as the result of intracisternal injection of kaolin, or by Novak and Walker (22) with serial ligation of the arterial supply to the brain. There is thus at least some evidence to favor the hypothesis that in essential hypertension there may be a primary cerebrovascular constriction accompanied by a secondary and compensatory hypertension which maintains a normal cerebral blood flow. If this be the primary mechanism, however, its modus operandi can hardly be through cerebral asphyxia, since there is no detectable change in the chemical composition of internal jugular blood. There is equal plausibility, however, in two alternative concepts : that the increased cerebrovascular resistance is simply part of a generalized vasoconstriction which raises the blood pressure, or that it occurs in response to a hypertension originating elsewhere and is mediated by a hypothetical intrinsic regulating mechanism, the effect of which is to maintain a normal cerebral blood flow.

It is possible that further investigations, now under way, of the cerebral circulation in hypertension, especially in its response to alterations in the level of arterial blood pressure, or to block of the cranial sympathetic supply, may shed further light on the relationships between hypertension and the marked increase in cerebrovascular resistance which accompanies it.

\section{SUM MARY}

1. Studies are reported of cerebral blood flow, cerebral metabolism and cerebrovascular resistance in 13 patients with essential hypertension.

2. Despite a markedly elevated mean arterial blood pressure, cerebral blood flow was within normal limits, as was also cerebral oxygen consumption.

3. There was a marked and consistent increase in cerebrovascular resistance averaging $88 \%$, which appeared to be roughly correlated with the grade of retinopathy. 


\section{ACKNOWLEDGMENT}

The authors wish to acknowledge the technical assistance of Miss Hannah T. Broomell and Mrs. Clara Belle Rhode, and the excellent cooperation from the medical and surgical staffs of the Hospital of the University of Pennsylvania.

\section{BIBLIOGRAPHY}

1. Bell, E. T., and Clawson, B. J., Primary (essential) hypertension; study of 420 cases. Arch. Path., 1928, 5, 939.

2. Murphy, F. D., Grill, J., Pessin, B., and Maxon, G. F., Essential hypertension; a clinical and morphological study of 375 cases. Ann. Int. Med., 1932, 6, 31.

3. Flaxman, N., The course of hypertensive heart disease: I. Age of onset, development of cardiac insufficiency, duration of life, and cause of death. Ann. Int. Med., 1936, 10, 748.

4. Williams, D., and Lennox, W. G., The cerebral bloodflow in arterial hypertension, arteriosclerosis, and high intracranial pressure. Quart. J. Med., 1939, 8, 185.

5. Raab, W., Hirnblutuntersuchungen bei Hypertonie. Ztschr. f. klin. Med., 1931, 115, 577.

6. Kety, S. S., and Schmidt, C. F., The determination of cerebral blood flow in man by the use of nitrous oxide in low concentrations. Am. J. Physiol, 1945, 143, 53.

7. Kety, S. S., and Schmidt, C. F., The nitrous oxide method for the quantitative determination of cerebral blood flow in man; theory, procedure and normal values. J. Clin. Invest., 1948, 27, 476.

8. Kety, S. S., and Schmidt, C. F., Cerebral blood flow and cerebral oxygen consumption in five patients with hypertension. Am. J. M. Sc., 1946, 212, 124.

9. Peters, J. A., and Van Slyke, D. D., Quantitative Clinical Chemistry. Williams \& Wilkins, Baltimore, 1931.

10. Bradley, S. E., and Smith, H. W., Peripheral vascular resistance in normal resting man. Unpublished work quoted by Goldring and Chasis (12).
11. Goldring, W., Chasis, H., Ranges, H. A., Lauson, H., and Cournand, A., Unpublished work quoted by Goldring and Chasis (12).

12. Goldring, W., and Chasis, H., Hypertension and $\mathrm{Hy}-$ pertensive Disease. The Commonwealth Fund, New York, 1944.

13. Steele, J. M., and Kirk, E., The significance of the vessels of the skin in essential hypertension. J. Clin. Invest., 1934, 13, 895.

14. Pickering, G. W., The peripheral resistance in persistent arterial hypertension. Clin. Sc., 1936, 2, 209.

15. Prinzmetal, M., and Wilson, C., The nature of the peripheral resistance in arterial hypertension with special reference to the vasomotor system. J. Clin. Invest., 1936, 15, 63.

16. Goldring, W., Chasis, H., Ranges, H. A., and Smith, H. W., Effective renal blood flow in subjects with essential hypertension. J. Clin. Invest., 1941, 20, 637.

17. Wilkins, R. W., Culbertson, J. W., and Inglefinger, F. J., The effects of splanchnicectomy upon hepatic function and blood flow in hypertensive patients. Proc. Am. Soc. for Clin. Invest., May, 1947, J. Clin. Invest., 1947, 26, 1200.

18. Kety, S. S., Harmel, M. H., Broomell, H. T., and Rhode, C. B., The solubility of nitrous oxide in blood and brain. J. Biol. Chem., 1948, 173, 487.

19. Cushing, H., Some experimental and clinical observations concerning states of increased intracranial tension. Am. J. M. Sc., 1902, 124, 375.

20. Kety, S. S., Shenkin, H. A., and Schmidt, C. F., The effect of increased intracranial pressure on cerebral circulatory functions in man. J. Clin. Invest., 1948, 27, 493.

21. Dixon, W. E., and Heller, H., Experimentelle Hypertonie durch Erhöhung des intrakraniellen Druckes. Arch. f. exper. Path. u. Pharmakol., 1932, 166, 265.

22. Nowak, S. J. G., and Walker, I. J., Experimental studies concerning the nature of hypertension; their bearing on surgical treatment. New England J. Med., 1939, 220, 269. 